\title{
Case Report: Mass Casualty Response to Mine Explosion: A Case Report in Iran
}

\author{
Ahmad Reza Raeisi' ${ }^{1}$, Ali Mohajervatan ${ }^{2 *}$ (D), Zahra Mehraein Nazdik \\ 1. Health Management and Economics Research Center, Isfahan University of Medical Sciences, Isfahan, Iran. \\ 2. Department of Disaster and Emergency Health, School of Management and Medical Information Sciences, Isfahan University of Medical Sciences, \\ Isfahan, Iran. \\ 3. Department of Management, School of Management and Economics, Shahid Bahonar University of Kerman, Kerman, Iran.
}

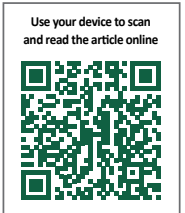

Citation: Raeisi AR, Mohajervatan A, Mehraein Nazdik Z. Mass Casualty Response to Mine Explosion: A Case Report in Iran. Health in Emergencies and Disasters Quarterly. 2019; 4(3):173-178. http://dx.doi.org/10.32598/hdq.4.3.173

doi: : http://dx.doi.org/10.32598/hdq.4.3.173

\section{(1) (8)}

Article info:

Received: 12 Oct 2018

Accepted: 28 Feb 2019

Available Online: 01 Apr 2019

\section{Keywords:}

Triage, Emergency Medical Services (EMS), Mass Casualty Incident (MCI), Mine Explosion

\section{A B S TRACT}

Background: On May 3, 2017, at 11:58 AM local time, an explosion occurred in the ZemestanYurt coal mine in Azadshahr City of Golestan Province, northern Iran, which resulted in mass casualty incident.

Materials and Methods: In total, more than 126 miners were affected. Of them, 43 miners were killed, 73 other workers who helped their coworkers were also injured and taken to the hospital, and 10 injured people received on-site prehospital medical care. Many defects in the response phase were identified in the scene management and the triage.

Results: It seems necessary to establish a response plan for mass casualty incident, hold regular education, and plan to prepare involved units for appropriate responses.

Conclusion: These measures are the first steps needed to improve preparedness and response to a mass casualty incident.

\section{Introduction}

arious types of events and casualties happen all over the world: chemical, bioI logical and nuclear accidents, explosions. Also, there are common occurrences, such as traffic accidents, fires, and mass gatherings [1]. Despite the availability of valuable medical resources in areas affected by these events, their consequences are tending to increase the deaths of the victims; the main reason is unpreparedness of the health centers [2]. Providing timely health care services can play a vital role in increasing the number of survivors and reducing mortality rate and disabilities [3].

The main problem in surveillance of mass casualty is not the number of injured who need treatment but the quality and the way of using available resources [4]. Accordingly, planning and management are the most critical elements for optimal allocation of limited resources in such incidents [5]. Management of these conditions is a complex process that includes coordination of therapeutic interventions and effective triage [6-8]. This

* Corresponding Author:

Ali Mohajervatan, PhD. Student.

Address: Department of Disaster and Emergency Health, School of management and Medical Information Sciences, Isfahan University of Medical Sciences, Isfahan,Iran.

E-mail: mohajervatanali@gmail.com 
objective will be achieved if health centers are at least prepared for different incidents [9]. In addition, previous studies have shown that the experience of doctors or prehospital staff who are trained and worked in prehospital settings can be useful during an accident $[4,10,11]$.

On the other hand, experiences in Iran have revealed that coping with disasters and their impact is a challenge for authorities. By reviewing the previous events, it can be seen that the disaster management system of Iran has always been challenged by serious problems [12]. Therefore, the evaluation and management of incidents in current societies and responsible and accountable organizations are necessary [13]. In this paper, we have reviewed the response of the healthcare system and its effective factors to the mine blast accident (May 3, 2017, Azadshahr City, Golestan Province) to provide more useful information for future responses.

\section{Materials and Methods}

The data were collected by field observation, analyzing documents of the prehospital emergency and local hospital, and a group discussion with the presence of operational staff.

In this research, we are bound to respect the privacy of the involved organizations. Any disclosure of information obtained from organizations is based on their in- formed consent. The researchers are required to publish their study results (whether negative or positive) honestly, accurately, and completely.

\section{Results}

On Wednesday, May 3, 2017, at 11:58 AM local time, an explosion occurred in Zemestan-Yurt coal mine in Azadshahr City of northern Iran. As a result, 43 miners were killed, and 73 were injured (Table 1).

The incident affected more than 126 miners. A total of 43 people were killed by a mine blast, and more than 73 people who were trying to help coworkers were injured and transferred to the hospital. Ten injured people received on-site prehospital medical care. The law enforcement units were the first to arrive at the scene of the accident. Then, 6 prehospital emergency ambulances arrived at the accident site (Figure 1) .

At the beginning of the incident, law enforcement set the perimeters around the accident site. The first prehospital emergency ambulance arrived 23 minutes after the explosion. Prehospital emergency personnel, along with volunteers, were helping workers who had been injured and had respiratory problems. Local volunteers and relief forces removed the injured from the mine and transferred them to the collection zone. An initial triage was carried out there. If a person had serious problems, he

Table 1: Mass casualty caused by mine explosion

\begin{tabular}{|c|c|c|c|c|}
\hline Date & Location & Death & Injury & Responsive organizations \\
\hline May 3, 2017 & $\begin{array}{c}\text { Golestan Province, } \\
\text { northern Iran }\end{array}$ & 43 & 73 & $\begin{array}{c}\text { Emergency medical services, Red Crescent, } \\
\text { Police, Fire station, District hospital, Local } \\
\text { volunteers }\end{array}$ \\
\hline
\end{tabular}

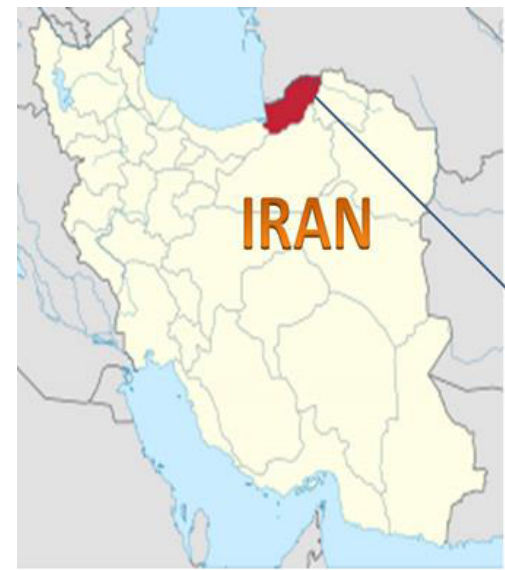

Figure 1. Golestan Province map

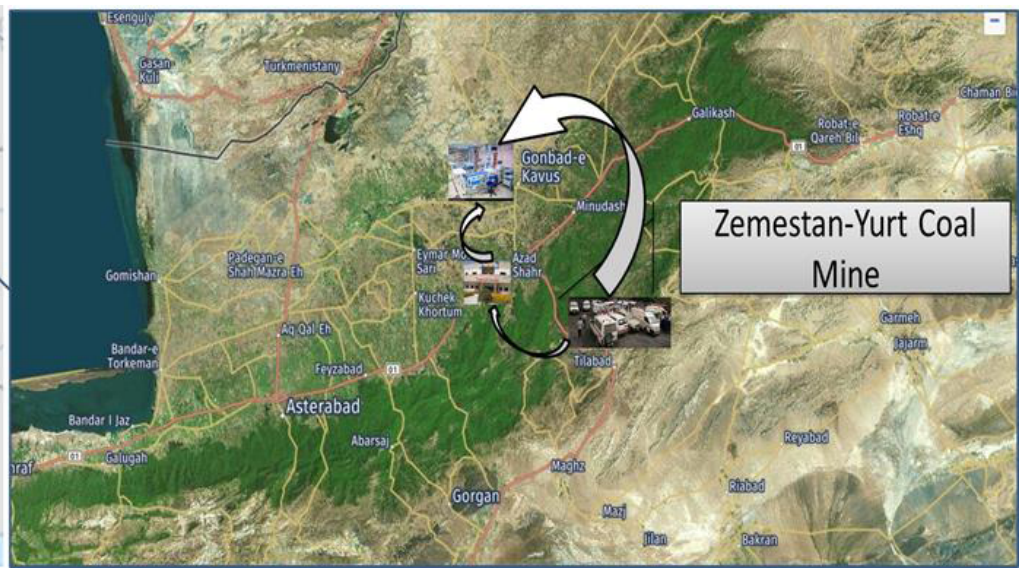

Hilealth in Emergencies and D]isasters [Qluarterly 


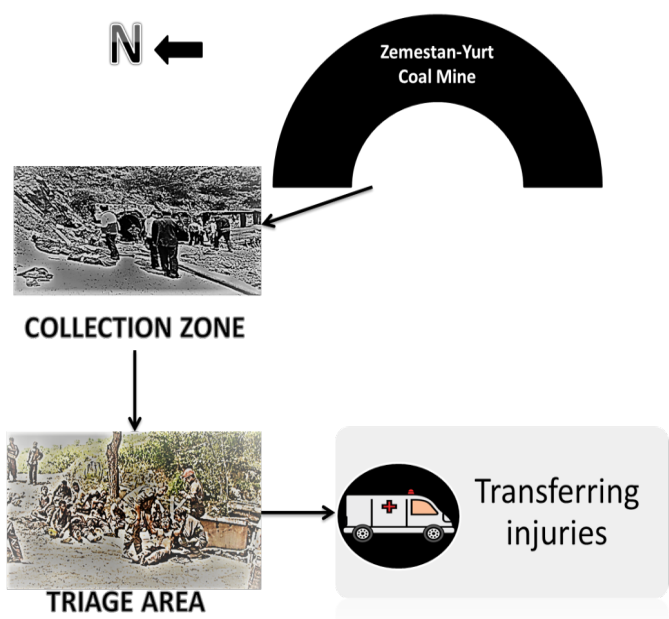

Figure 2. Map scene

would be moved to the triage location in the northern part at a distance of $15 \mathrm{~m}$ from the mine span (Figure 2).

In this place, the contaminated clothing was removed by locals and relief forces, and the secondary triage process was carried out by the local physician at the scene. After the secondary triage, if it were necessary, the injured person would be transferred to a local hospital by ambulances of emergency medical services or other relief agencies which were available at the scene. Other patients in the triage category were also transported to the district hospital with the coordination of the triage officer [14].

The nearest hospital was about $25 \mathrm{~km}$ from the site of the explosion. The incident information and the number of expected injuries had been reported to the hospital by the prehospital emergency center of the region. The emergency operation center had also coordinated the necessary follow-up actions. A total of 55 injured patients were hospitalized in the nearest hospital, and the remaining injured workers were taken to other nearby hospitals. Twenty-eight patients from a total of 55 injured were hospitalized, and the rest were discharged in less than 6 hours.

The most important steps taken by the hospital in response to the incident can be summarized as follows: calling hospital staff for attendance, using other staff in the emergency room, discharging inpatients and stop the outpatients' examination, using the companion chairs as extra beds, informing via whiteboard at the hospital entrance to relatives of patients, co-operation and coordination of the hospital's security with the police to control congestion and transportation of relief vehicles [15].
During the first 2 hours of the incident, there was no indication of the trapped people at the site of the explosion or the estimated number of fatalities. The coordination of the relief forces was initially unsatisfactory. The safety of the scene was not monitored, and there was a possibility of a secondary incident at any moment. The Incident Command Post (ICP) was set up at a tent after about 3 hours with the attendance of the highest provincial authorities (Table 2). Strategies for a comprehensive response were developed and informed to the organizations.

\section{Discussion}

Evaluations of measures in the Zemestan-Yurt incident showed that provision of prehospital services in the first hour was carried out with a focus on triage, treatment, and transportation of injured considering the unstable weather and the mountainous area. Using local forces to transfer the injured had reduced waiting times for services [14]. Meanwhile, evidence showed that most prehospital and hospital care facilities were not prepared to manage mass casualty incidents $[15,16]$. It should be remembered that the response to such events should not be limited to triage, treating, and transferring injured people. These incidents require Incident Action Plans (IAP), allocating resources, disaster management systems, and staff protections [17].

The evaluations revealed that the failures to develop an IAP, establish a unified command structure, support staff and continue the response plans (the recovery of operational forces in the first 24 hours) had occurred in this incident [14]. The Furbee report showed that $38 \%$ of the emergency service organizations had faced with at least one incident with mass injuries, and they 
Table 2. Summary of challenges (five categories of incident management problems)

\begin{tabular}{c} 
Categories \\
\hline Lack of incident action plan \\
Lack of a unified command system \\
Lack of valid information \\
Lack of safety and security \\
Lack of coordination, collaboration, and integration \\
\hline
\end{tabular}

were confused in providing responses and allocating appropriate resources $[17,18]$. In addition, the report points out that many prehospital services organizations did not pass the proper drills to determine their level of preparedness $[17,18]$.

Our survey reported that most organizations' confusion was seen at the beginning of a response to the accident because of the limited reliable data about the number of trapped workers and the lack of experience with the same events. Of course, this confusion has gradually diminished with the presence of provincial authorities [14]. Therefore, preparedness and exercise of the responsible organizations are necessary.

One of the problems faced by the massive casualties is identifying people with severe injuries, carrying out basic measures to preserve life, and evacuating casualties without unnecessary procrastination [8]. The identification of people with severe injuries, primary care measures, and evacuation of the injured in the mine appeared during the same hours. As a result, most of the casualties moved out of the area during the same hours without delay in providing services and only by taking measures to preserve life. This action was very effective in facilitating the search and rescue process by other organizations [14].

riage is one of the most important elements in response to these mass injuries, which is affected by various factors in the provision of prehospital services and should be well identified and documented [8, 19]. The Simple Triage And Rapid Treatment (START) triage was used in the Zemestan-Yurt mine accident, and it was effective in the evacuation of the injured in the early hours [17]. But it seemed that attention to other important aspects of the accident (such as the safety of scene due to gas leakage from the mine, interagency cooperation and coordination, and the involvement of non-specialists) had been less focused on the response process [14]. As a result, we should embark on identifying, evaluating, and documenting these measures.

Examining the documented images of the incident indicated that the distance intended to hold, triage, and send the injured were less than $20 \mathrm{~m}$ away from the mine [14]. On the other hand, lack of control and setting up perimeters to the site of the incident caused overcrowding in the region, which made problems in the service process as well as increased risk of life-threatening secondary incident (prehospital emergency report and published pictures in local news agencies) that should be considered.

\section{Conclusion}

The main problem in the early hours of Azadshahr mine accident was related to the integrated management of the relief forces. The START triage protocol used by the prehospital and hospital emergency room was effective in evacuating the injured from the incident site and admitting to the hospital. But the lack of integrated command resulted in the arrival of unskilled staff to the site and the creation of secondary injuries. Therefore, it is essential to create a response program to the mass casualties, as well as regular training and planning in preparing the responsible units for appropriate responses. These activities are the first steps that are needed to improve preparedness and response to incidents.

Access to the reports of the involved organizations was one of the study limitations. Since some parts of data had been collected through direct observation, there might be other angles of inaccuracy, which also outweigh the research constraints. 


\section{Ethical Considerations}

\section{Compliance with ethical guidelines}

There was no ethical considerations to be considered in this research.

\section{Funding}

This research did not receive any specific grant from funding agencies in the public, commercial, or not-forprofit sectors.

\section{Authors' contributions}

Conceptualization: All Authors; Methodology: All Authors; Investigation: All Authors; Writing Original Draft: Ali Mohajervatan, Zahra Mehraein Nazdik; Funding Acquisition: Ali Mohajervatan; Writing Review \& Editing: all Authors; Supervision: Reza Raeisi Ahmad

\section{Conflict of interest}

The authors declared no conflict of interest.

\section{Acknowledgments}

The authors of this study express their appreciation toward the sincere cooperation of Golestan Emergency Medical Services.

\section{References}

[1] World Health Organization. Mass casualty management systems: Strategies and guidelines for building health sector capacity. Geneva: WHO Document Production Services; 2007.

[2] Kuisma M, Hiltunen T, Määttä T, Puolakka J, Boyd J, Nousila-Wiik M, et al. Analysis of multiple casualty incidents-a prospective cohort study. Acta Anaesthesiologica Scandinavica. 2005; 49(10):1527-33 [DOI:10.1111/j.1399 6576.2005.00761.x] [PMID]

[3] Arab M, Zeraati H, Akbari Haghighi F, Ravangard R. [A study on the executive managers' knowledge and performance, and their hospitals preparedness against earthquake events and their relationships at public hospitals (affiliated by Tehran University of Medical Sciences (TUMS) 20052006)(Persian)]. Journal of Health Administration. 2009; 11(34):7-14

[4] Aylwin CJ, König TC, Brennan NW, Shirley PJ, Davies G, Walsh MS, et al. Reduction in critical mortality in urban mass casualty incidents: Analysis of triage, surge, and resource use after the London bombings on July 7, 2005.
The Lancet. 2007; 368(9554):2219-25. [DOI:10.1016/S01406736(06)69896-6]

[5] Antommaria AHM, Powell T, Miller JE, Christian MD, Task Force for Pediatric Emergency Mass Critical Care. Ethical issues in pediatric emergency mass critical care. Pediatric Critical Care Medicine. 2011; 12 (Suppl. 6):S163-8. [DOI:10.1097/PCC.0b013e318234a88b] [PMID]

[6] Frykberg ER. Triage: Principles and practice. Scandinavian Journal of Surgery. 2005; 94(4):272-8. [DOI:10.1177/1457496 90509400405] [PMID]

[7] Risavi BL, Terrell MA, Lee W, Holsten DL. Prehospital Mass-Casualty Triage Training-Written Versus Moulage Scenarios: How Much Do EMS Providers Retain? Prehospital and Disaster Medicine. 2013; 28(3):251-6. [DOI:10.1017/ S1049023X13000241] [PMID]

[8] Lampi M, Junker J, Berggren P, Jonson C-O, Vikström T. Pre-hospital triage performance after standardized trauma courses. Scandinavian Journal of Trauma, Resuscitation and Emergency Medicine. 2017; 25:53. [DOI:10.1186/s13049017-0395-8] [PMID] [PMCID]

[9] Debacker M, Hubloue I, Dhondt E, Rockenschaub G, Rüter A, Codreanu T, et al. Utstein-style template for uniform data reporting of acute medical response in disasters. PLOS Currents. 2012; 4: e4f6cf3e8df15a. [DOI:10.1371/4f6cf3e8df15a]

[10] Bøtker MT, Bakke SA, Christensen EF. A systematic review of controlled studies: do physicians increase survival with prehospital treatment? Scandinavian Journal of Trauma, Resuscitation and Emergency Medicine. 2009; 17:12 [DOI:10.1186/1757-7241-17-12] [PMID] [PMCID]

[11] Hyde P, Mackenzie R, Ng G, Reid C, Pearson G. Availability and utilisation of physician-based pre-hospital critical care support to the NHS ambulance service in England, Wales and Northern Ireland. Emergency Medicine Journal. 2012; 29(3):177-81. [DOI:10.1136/emj.2010.106963] [PMID] [PMCID]

[12] Mohebbifar R, Tabibi S, Asefzadeh S. [Designing a structure of disaster management for Iran (Persian)]. Journal of Health Administration. 2008; 11(33):47-56.

[13] Vahedparast H, Ravanipour M, Hajinezhad F, Kamali F, Gharibi T, Bagherzadeh R. [Assessing hospital disaster preparedness of bushehr province (Persian)]. Iranian South Medical Journal. 2013; 16(1):69-76.

[14] EMS \& disaster management center of Golestan Province. Pre-hospital repot: Per-hospital performance report in explotion mine incident occurred in Zemestan-Yurt Coal Mine, AzadShahr City. Golestan: EMS \& disaster management center of Golestan province; 2017.

[15] Dal Ponte ST, Dornelles CF, Arquilla B, Bloem C, Roblin P. Mass-casualty response to the Kiss nightclub in Santa Maria, Brazil. Prehospital and Disaster Medicine. 2015; 30(1):93-6. [DOI:10.1017/S1049023X14001368] [PMID]

[16] Hsu EB, Jenckes MW, Catlett CL, Robinson KA, Feuerstein $\mathrm{C}$, Cosgrove SE, et al. Effectiveness of hospital staff mass-casualty incident training methods: A systematic literature review. Prehospital and Disaster Medicine. 2004; 19(3):191-9. [DOI:10.1017/S1049023X00001771] [PMID]

[17] Glow SD, Colucci VJ, Allington DR, Noonan CW, Hal EC. Managing multiple-casualty incidents: A rural medi- 
cal preparedness training assessment. Prehospital and Disaster Medicine. 2013; 28(4):334-41. [DOI:10.1017/ S1049023X13000423] [PMID]

[18] Furbee PM, Coben JH, Smyth SK, Manley WG, Summers DE, Sanddal ND, et al. Realities of rural emergency medical services disaster preparedness. Prehospital and Disaster Medicine. 2006; 21(2):64-70. [DOI:10.1017/ S1049023X0000337X] [PMID]

[19] Yin H, He H, Arbon P, Zhu J. A survey of the practice of nurses' skills in Wenchuan earthquake disaster sites: Implications for Disaster Training. Journal of Advanced Nursing. 2011; 67(10):2231-8. [DOI:10.1111/j.1365-2648.2011.05699.x] [PMID] 